\title{
Enfrentamento à violência obstétrica: contribuições do movimento de mulheres negras brasileiras
}

\author{
Confronting obstetric violence: contributions from the black \\ Brazilian women's movement
}

Jussara Francisca de Assis dos Santos*

\begin{abstract}
Resumo - O presente artigo tem por objetivo ressaltar a necessidade de apropriação das contribuições do movimento de mulheres negras por parte de gestoras/es e profissionais de saúde para a efetivação da equidade racial no que se refere à assistência ao parto. A reflexão trazida aqui é motivada pelos resultados da pesquisa realizada no âmbito do doutoramento da autora, cujo objeto foi o enfrentamento à violência obstétrica contra mulheres negras numa maternidade do município do Rio de Janeiro. A metodologia utilizada pautou-se em 15 entrevistas semiestruturadas entre gestoras e profissionais de saúde das áreas de Serviço Social, enfermagem e medicina. O método de análise teve como base a interpretação dos sentidos atribuídos à violência obstétrica e sua relação com a dimensão racial. Não foram identificadas ações que privilegiassem a articulação com o movimento de mulheres negras, tendo em vista sua importância no combate à violência obstétrica.
\end{abstract}

Palavras-chave: mulheres negras; violência obstétrica; movimento social; saúde da população negra.

\begin{abstract}
This article aims to highlight the need for appropriation of the contributions of the black women's movement by health managers and professionals to the realization of racial equity in regard to childbirth assistance. The ideas presented here are motivated by the results of the research carried out within the scope of the author's doctorate research, whose object was to confront obstetric violence against black women in a maternity hospital in the city of Rio de Janeiro. The methodology used was based on 15 semi-structured interviews between health managers and professionals in the areas of social work, nursing and medicine. The method of analysis was based on the interpretation of the meanings attributed to obstetric violence and its relationship with the racial aspect. No actions were identified that favored articulation with the black women's movement, considering its importance in combating obstetric violence.

Keywords: black women; obstetric violence; social movement; health of the black population.
\end{abstract}

\footnotetext{
* Doutora em Serviço Social (Universidade Federal do Rio de Janeiro). Professora da Escola de Serviço Social da Universidade Federal Fluminense, Niterói. E-mail: Ifjussara2015@gmail.com. ORCID: https://orcid.org/0000-00024819-775X.
} 


\section{Introdução}

As reflexões trazidas neste artigo resultam de parte da tese de doutorado intitulada Enfrentamento à violência obstétrica contra mulheres negras numa maternidade pública municipal do Rio de Janeiro na perspectiva de gestoras (es) e profissionais de saúde. Para tanto, a pesquisa qualitativa, baseada em estudo de caso, contou como método de análise a interpretação de sentidos (GOMES, 2016) em torno do conceito de violência obstétrica atrelado à dimensão racial.

Foram realizadas 15 entrevistas semiestruturadas entre gestoras e profissionais de saúde das áreas de Serviço Social, enfermagem e medicina ${ }^{1}$. A escolha da maternidade pesquisada teve como um dos critérios o fato de estar localizada numa área programática (AP) cujo índice de morte materna no ano de 2016 foi o mais elevado do município do Rio de Janeiro. A partir dos sentidos que foram relacionados ao objeto de estudo, atribuíramse ideias associadas ao entendimento entre violência obstétrica e viés racial. Identificou-se que a maioria das/os entrevistadas/os revelou que mulheres negras e brancas seriam atendidas igualmente e, caso houvesse algum tipo de discriminação, essa se daria pela dimensão meramente socioeconômica.

Ressalta-se que o lócus do estudo é caracterizado por se situar numa área periférica da cidade cuja população prioritária é negra. A superposição da classe em detrimento da raça/cor é comum no Brasil, onde a crença na democracia racial tende a escamotear as profundas desigualdades e discriminações com as quais grande parte da população não branca é obrigada a conviver.

Descortinar o mito da democracia racial a partir da realidade sócio-histórica da população negra e, sobretudo, das mulheres pretas, pardas e indígenas tem se configurado como pauta política do movimento de muIheres negras no Brasil. O objetivo deste artigo é ressaltar a necessidade de apropriação das contribuições do movimento de mulheres negras por parte de gestoras/es e profissionais de saúde para a efetivação da equidade racial no que se refere à assistência ao parto.

A pesquisa de doutorado procurou identificar ações institucionais e individuais que pudessem considerar a articulação entre violência obstétrica e dimensão racial, tendo em vista a necessidade de pontuar as especificidades das mulheres no que tange a suas localizações de classe, raça/ cor e gênero. Neste contexto, verifica-se que a violência obstétrica tem impactado, sobremaneira, a vida de mulheres pretas e pardas brasileiras, demonstrando como a interseccionalidade de opressões é capaz de se manifestar e se materializar no período gravídico puerperal, colocando em risco o direito à vida.

\footnotetext{
1 A referida pesquisa foi aprovada pelo Comitê de Ética em Pesquisa do Centro de Filosofia e Ciências Humanas (CFCH) da UFRJ, CAAE 88996018.5.0000.5582, e pelo Comitê Coparticipante da Secretaria Municipal de Saúde do Rio de Janeiro, CAAE 88996018.5.3001.5279.
} 
A violência obstétrica é tida como uma violência de gênero. Tanto no Brasil quanto em outros países da América Latina o termo é utilizado para demonstrar as formas de desrespeito às mulheres grávidas, parturientes e puérperas ocorridas no âmbito das instituições de saúde, sejam elas públicas ou privadas. Com o objetivo de investigar a situação da violência contra a mulher no Brasil, foi instaurada, entre 2011 e 2012, a Comissão Parlamentar Mista de Inquérito (CPMI), do Senado Federal. Em 2013, o relatório final da referida CPMI definiu como atos característicos de violência obstétrica: a negligência, a violência verbal (grosserias, ameaças e humilhações intencionais), violência física (incluindo a não utilização de analgesia quando necessário e a realização de cirurgias desnecessárias e indesejadas) (REDE PARTO DO PRINCÍPIO, 2012).

O fenômeno violência obstétrica promoveu e promove discussões e sentimentos profundos porque impacta idealizações em torno do gestar e parir, colocando em risco o direito à vida das mulheres e de seus bebês. Contraditoriamente, mulheres e, fundamentalmente, mulheres pretas e pardas têm suas humanidades colocadas em xeque quando são desconsideradas suas histórias, opiniões, sentimentos e direitos ao serem alvos da violência obstétrica. O verbo enfrentar guarda os seguintes significados: pôr ou colocar (-se) diante de; defrontar; encarar sem medo (ENFRENTAR, 2020).

Por um lado, cabe o questionamento quanto à capacidade de enfrentar a violência obstétrica, que ganha potencialidade com a dimensão racial por parte de gestoras/es e profissionais de saúde. Será que este grupo tem incorporado as especificidades das mulheres negras em suas formas de atuação profissional? Por outro lado, encarar sem medo tem sido o objetivo do movimento de mulheres negras quando se trata de defesa à vida e ao bem viver. Historicamente, as lutas políticas travadas pelas negras têm pautado o direito à saúde reprodutiva e sexual. Em que medida tais contribuições têm estado presentes na assistência obstétrica às mulheres negras no Brasil, sobretudo no âmbito do Sistema Único de Saúde (SUS)?

A articulação de mulheres negras enquanto movimento social tem sido fundamental para o enfrentamento das desigualdades com as quais grande parte das mulheres deste grupo se depara nos serviços de saúde. A história das mulheres negras no Brasil é marcada por um processo violento que insiste em permanecer na atualidade. Desde a travessia transatlântica, no interior dos tumbeiros e navios negreiros, as mulheres negras são alvo de violência por terem sido, sumariamente, separadas de seus filhos e violentadas sexualmente, tendo seus partos desconsiderados. De acordo com Almeida (2014), estas raízes remontam à emergência do Estado moderno e colonial, e suas ideologias e práticas discriminatórias são reconfiguradas ao longo do tempo a partir de uma perspectiva capitalista.

Estudo de base nacional realizado por Leal et al. (2017) revela que puérperas de cor preta possuíram maior risco de terem um pré-natal inadequado ao se comparar às puérperas brancas. Além disso, foi constatado 
também que para as mulheres pretas há maior incidência de falta de vinculação à maternidade, ausência de acompanhante, maior peregrinação para o parto e menos anestesia local para episiotomia. A mesma pesquisa revelou que as puérperas declaradas de cor parda também tiveram maior risco de terem um pré-natal inadequado e falta de acompanhante quando comparadas às brancas.

Ao pesquisar os sentidos atribuídos ao enfrentamento à violência obstétrica contra mulheres negras, verificou-se que o conceito de igualdade de condições, numa perspectiva liberal, colocava as mulheres atendidas naquela maternidade dentro do mesmo universo, ou seja, as pautas relativas às especificidades das mulheres negras, tais como suas condições de trabalho, moradia, saúde, território, religião etc., não faziam parte da concepção de saúde pela qual grande parte das/os gestoras/es e profissionais entrevistadas/os se orientava. Estes aspectos têm sido questionados pelas mulheres negras que contribuem, epistemológica e politicamente, para efetivação do princípio de equidade, tida como uma das diretrizes do SUS.

\section{O movimento de mulheres negras brasileiras e as suas contribuições para a política de saúde}

A concepção de direitos sociais e humanos parece não estar concretizada para a população negra no Brasil. Neste contexto, a resistência das mulheres negras sempre esteve presente para a garantia à vida. A articulação feminina negra não é recente. Pode-se considerar que desde a travessia do Continente Africano para as Américas existiram muitas formas de resistência. Werneck (2009, p. 77), ao discorrer sobre a diáspora africana e o papel fundamental das mulheres negras neste processo, afirma que:

Na formação e expansão desta diáspora, as articulações empreendidas tinham e têm como âncora principal a luta contra a violência do aniquilamento - racista, heterossexista e eurocêntrica - com vistas a garantir nossa participação ativa no agenciamento das condições de vida para nós mesmas e para o grupo maior a que nos vinculamos.

A autora afirma que se não fosse a resistência e o imperativo de sobrevivência ao cenário violento possibilitado pela espoliação do povo negro africano talvez não existissem as mulheres negras. A resistência é parte intrínseca à identidade negra feminina, já que as experiências de desfavorecimento social, político, econômico e cultural vêm fazendo parte de seu cotidiano desde a travessia transatlântica. Sendo assim, a categoria mulher negra é histórica e a luta contra as desigualdades que a permeia é secular.

Este fato pode ser exemplificado pela duração e resistência de mitos que atravessaram o Atlântico sob condições desumanas, contestando 
o terror racial, a violência e as investidas de conversão euro-cristã. Nanã, lemanjá, lansã, Oxum e Obá são algumas das divindades tradicionais de resistência feminina negra existente desde tempos imemoriais. Além delas, existiram e ainda existem as sociedades secretas (Geledé, Eleekó) e as irmandades femininas negras (Boa Morte - BA). Werneck (2009, p. 79) destaca a figura da lalodé, que se refere à "liderança feminina que, segundo registros historiográficos precários, existiu nas cidades iorubas pré-coloniais". Quanto ao protagonismo histórico das mulheres negras, Werneck (2009, p. 80) segue argumentando que:

Chamar atenção para ialodê, para as divindades aqui assinaladas e para as diferentes associações de mulheres, é um modo de destacar exemplos das formas políticas e organizacionais cuja origem precedeu a invasão escravista e colonial. Estes reafirmavam e reafirmam a política como um atributo feminino desde a época anterior ao encontro com o ocidente. Diga-se de passagem, ao contrário do que afirmam muitas e muitos, a ação política das mulheres negras nas diferentes regiões não foi novidade inaugurada pela invasão europeia e a instauração da hegemonia cristã. O que torna fácil compreender que tais ações precederam a criação do feminismo. No entanto, seu grau de influência sobre a criação deste ainda permanece invisível.

O movimento de mulheres negras demonstra que, ao longo de sua trajetória, o direito à saúde é uma de suas prioridades de luta. Nos idos de 1950, a influência do grupo de mulheres organizadas do Teatro Experimental do Negro (TEN) demonstrava a preocupação, mas, ao mesmo tempo, oferecia estratégias para o acesso às maternidades:

A todas nós mulheres negras, compete modificar este quadro sombrio. Como? Nada de desanimo quando uma maternidade, por exemplo, negar o ingresso. Devemos procurar o diretor do estabelecimento, insistir, usar todos os meios e remover as dificuldades, ainda mesmo que sejam motivadas por discriminação de cor [...]. (NASCIMENTO, 2003, p. 303).

Ao tratar a saúde reprodutiva de mulheres negras e a contribuição do movimento social ligado a este grupo, faz-se necessário destacar os esforços e os importantes investimentos do mesmo no que tange à Política Nacional de Saúde Integral da População Negra (PNSIPN - BRASIL, 2013). O cenário para a consolidação da PNSIPN começa a se delinear no final dos anos 1980 e início da década de 1990. Neste momento, duas campanhas importantes foram desenvolvidas pelo movimento negro e pelo movimento de mulheres negras. A primeira delas, chamada Não matem nossas crianças, denunciava o extermínio de crianças e jovens negros pelos chamados grupos de extermínio. Posteriormente, tomou corpo a Campanha nacional contra a esterilização em massa de mulheres negras, com o slogan Esterilização 


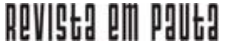

\} ENFRENTAMENTO À VIOLÊNCIA - SANTOS, J. F. A. \}

DOI: $10.12957 /$ rep.2021.56082

das mulheres negras: do controle da natalidade ao genocídio do povo negro, liderada pelo Programa de Mulheres do Centro de Articulação de Populações Marginalizadas do Rio de Janeiro (LOPES; WERNECK, 2009). Com isso, segundo Araújo (2001, p. 1):

[...] a esterilização cirúrgica foi o eixo que conseguiu unir e desencadear o processo de trabalho conjunto, que atualmente se estende às outras questões dos direitos reprodutivos, espaço onde o movimento de mulheres tem investido grande parte da sua energia.

O objetivo desta campanha era denunciar o caráter racista das iniciativas de controle populacional encapado pela ideia de planejamento familiar. Nos idos de 1991, o conceito de saúde da população negra ganha nova perspectiva, tendo como protagonistas os grupos religiosos de matrizes africanas, em que as mulheres negras tiveram, e continuam tendo, papel fundamental. Nesse ano há o lançamento do Projeto Odô Yâ, no Rio de Janeiro, onde o objetivo era o enfrentamento da epidemia de HIV/Aids. A partir desta iniciativa destaca-se a importância e a presença da população negra no combate da epidemia, fato que não era considerado no bojo das políticas públicas até então.

Em 1996, o quesito cor foi incluído nas declarações de nascidos vivos e óbito nos sistemas nacionais de informação sobre mortalidade. Além disso, houve o ganho da introdução do quesito cor na identificação daqueles sujeitos que porventura viessem a ser objeto de pesquisa envolvendo seres humanos ${ }^{2}$.

A III Conferência Mundial de Combate ao Racismo, Discriminação Racial, Xenofobia e Intolerância Correlata, ocorrida em Durban (África do Sul), no ano de 2001, contribuiu para o alargamento da discussão em torno da questão racial, intensificando as discussões sobre as formas de o setor público estabelecer medidas mais sólidas e sustentáveis de combate ao racismo e às desigualdades dele decorrentes. Assim, no mesmo ano realizouse o Workshop Inter-Agencial de Saúde da População Negra, que contou com a participação de estudiosas sobre desigualdades raciais na saúde, ativistas e especialistas do Programa das Nações Unidas para Desenvolvimento (PNUD), Organização Pan-Americana de Saúde (Opas) e Ministério Britânico para o Desenvolvimento Internacional (DIFD). Nessa época, foi elaborado o documento Política nacional de saúde da população negra: uma questão de equidade. Este documento teve como base estruturante a produção de conhecimento científico, a capacitação dos profissionais de saúde, a informação da população e a atenção à saúde. Este processo também resultou na criação do Programa de Combate ao Racismo Institucional (PCRI).

Em 21 de março de 2003 foi criada a Secretaria Especial de Políticas de Promoção da Igualdade Racial (Seppir). Em novembro do mesmo

\footnotetext{
${ }^{2}$ Resolução nº 196/96, que trata sobre as Normas de Ética em Pesquisas envolvendo Seres Humanos.
} 
ano, tal secretaria firmava o compromisso com o Ministério da Saúde de reconhecimento do racismo, que devia ser considerado como um dos determinantes sociais das condições de saúde. Essa iniciativa levou em consideração os processos de vulnerabilização a que diferentes segmentos populacionais são submetidos, sobretudo a população negra (LOPES; WERNECK, 2009). Ainda neste ano a participação dos representantes da população negra, sobretudo das mulheres negras organizadas, na $12^{\underline{a}}$ Conferência Nacional de Saúde garantiu a aprovação de cerca de 70 deliberações que contemplavam a questão racial, de gênero e geração que tinham como pano de fundo os princípios de não discriminação relacionada à orientação sexual, à filiação religiosa, ao estado ou à condição de saúde e à posse de alguma deficiência.

No ano de 2003 também ocorreu a criação da Secretaria Especial de Políticas para as Mulheres, que posteriormente teve sua nomenclatura definida como Secretaria de Políticas para Mulheres (SPM). O objetivo desse órgão foi criar políticas públicas que contribuam para a melhora da qualidade de vida de todas as brasileiras. A partir da relação transversal em todo o governo federal, esta secretaria procurou estabelecer parcerias com diversas instâncias governamentais na intenção de enfrentar as desigualdades e diferenças sociais, raciais, sexuais, étnicas e das mulheres deficientes.

Essa iniciativa foi considerada uma via importante no enfrentamento das iniquidades vivenciadas pelas mulheres negras, já que apresentou propostas para o combate às múltiplas formas de discriminação social, sobretudo racismo e sexismo, por meio de planos nacionais de políticas para as mulheres. Neste contexto, o segundo plano nacional foi aprovado pela II Conferência Nacional de Políticas para as Mulheres, realizada em agosto de 2007. Um dos eixos norteadores deste plano foi o eixo 9, que recebeu o título de Enfrentamento do racismo, sexismo e lesbofobia.

A instituição do Comitê Técnico de Saúde da População Negra, formado por militantes, pesquisadoras/es e especialistas em saúde da população negra, além de por representantes do Ministério da Saúde e suas instituições e Conselhos Nacionais de Secretários Estaduais e Municipais de saúde, se deu através da Portaria n. 2.632, de 15 de dezembro de 2004. Esse comitê teve a função de formular uma proposta de política nacional para essa parcela da população e contemplar ações específicas para as muIheres. A política maior que abarca todas estas ações é a PNSIPN, criada em 2006.

Estabelece-se, a partir deste momento, um novo patamar de atuação política no campo da saúde, uma vez que esta política consolida a responsabilização do SUS em promover ações afirmativas para alcançar a equidade em saúde para a população negra, destacando ações prioritárias, possibilitando interpelação direta e específica de gestores de saúde nos diferentes níveis e seu monitoramento detalhado 
por parte das organizações negras, do movimento negro e outros atores estratégicos. (LOPES; WERNECK, 2009, p. 15).

A solidificação da PNSIPN ocorre em 2007 com a realização 13 ${ }^{a}$ Conferência Nacional de Saúde. Neste momento, há a compreensão de que tal política deve ser entendida como um "instrumento de consolidação da unidade do sistema e da consecução dos princípios de integralidade e equidade na promoção e na atenção à saúde" (LOPES; WERNECK, 2009, p. 15). Instituída pela Portaria no 992, de 13 de maio de 2009, a PNSIPN tem como objetivo geral promover a saúde da população negra integralmente, priorizando a redução das desigualdades étnico-raciais, o combate ao racismo e à discriminação nas instituições e serviços do SUS.

Tendo em vista a necessidade de garantir os direitos que foram conquistados a partir de fortes lutas e resistências, em 2015 ocorreu em Brasília a Marcha das Mulheres Negras Contra o Racismo e a Violência e Pelo Bem Viver. O objetivo da manifestação, que reuniu cerca de 50 mil mulheres do Brasil e de algumas partes do mundo, foi reivindicar o direito à vida, à humanidade, bem como o direito a ter direitos, o reconhecimento e a valorização das diferenças.

Além disso, buscavam respostas mais efetivas por parte da sociedade e do Estado, tendo em vista a necessidade de justiça, equidade, solidariedade e bem-estar não só para mulheres negras, mas, também, para todas as mulheres que experimentam os efeitos do racismo, sexismo, lesbofobia, transfobia e outras formas de discriminação (GELEDES, 2015). As necessidades de saúde tiveram destaque e a mortalidade materna, cujos índices atingem 2,7 vezes mais pretas e pardas, foi questionada. Destacou-se a qualidade do atendimento prestado por profissionais de saúde em conjunto à falta de ações e de formação/capacitação para assistência aos riscos que as mulheres negras estão expostas no contexto do período gravídico-puerperal.

Mulheres pretas e pardas têm liderado a luta pela justiça reprodutiva no Brasil ao pontuarem a indissociabilidade entre saúde, direitos sexuais/reprodutivos e justiça social. O Guia de defesa popular da justiça reprodutiva organizado pelo Coletivo Margarida Alves Assessoria Popular revela que o termo foi popularizado na década de 1990, e sua definição é: "o direito humano de se manter a autonomia corporal pessoal, de ter filhos e de não ter filhos, e de educar os filhos que temos em comunidades seguras e sustentáveis" (COLETIVO MARGARIDA ALVES, 2020, p. 8). A justiça reprodutiva faz sentido para a realidade na qual as mulheres negras vivem no Brasil, já que defronta violações de direitos, sendo estes garantidos constitucionalmente. $\mathrm{O}$ direito à saúde é violado quando mulheres negras sofrem violência obstétrica, uma vez que coloca em risco sua integridade física e psicológica. A intersecção de opressões - gênero, raça/cor e classe - impacta o acesso à saúde e o exercício da sexualidade e da reprodução. 
[...] para tomarmos decisões sobre nossos corpos e nossa sexualidade e reprodução, precisamos ter acesso a recursos materiais, sociais e políticos que estão distribuídos desigualmente em nossa sociedade. E essa distribuição desigual e injusta não afeta apenas indivíduos, mas também famílias e comunidades inteiras. Sabe-se, por exemplo, que mulheres pretas possuem maior risco de ter um pré-natal inadequado, ausência de acompanhante e de receber menos orientações sobre o trabalho de parto e possíveis complicações na gravidez. Além disso, a maioria das mulheres que morrem por aborto são pobres, pretas ou pardas e com baixa escolaridade. (COLETIVO MARGARIDA ALVES, 2020, p. 9).

Neste contexto, faz-se necessário compreender as especificidades das mulheres negras a partir de uma perspectiva de totalidade e interseccional. É possível afirmar que o movimento de mulheres negras contribuiu para que o princípio da equidade fosse um dos pilares do SUS. A intenção é pontuar que direitos quanto à redistribuição, autonomia e liberdade reprodutiva, ou seja, com relação à saúde integral, devem ser deveres do Estado. Tal sentido deve ser incorporado na gestão e execução da política de saúde, assim como preconiza a PNSIPN.

\section{Desafios à vista: a incorporação das pautas das mulheres negras na agenda da assistência obstétrica}

Para pesquisar o enfrentamento à violência obstétrica contra muIheres negras numa maternidade municipal do Rio de Janeiro privilegiouse a metodologia da interpretação de sentidos, que, dentro da perspectiva da pesquisa qualitativa, objetiva a exploração do conjunto de opiniões do grupo a ser estudado, considerando sua dimensão sociocultural (GOMES, 2016). Para a reflexão proposta aqui será apresentada uma das ideias associadas ao núcleo de sentido diversidade. Este sentido relacionou-se às percepções acerca das particularidades e especificidades das mulheres que acessam os serviços da maternidade investigada. A intenção foi verificar em que medida as contribuições do movimento de mulheres negras perpassavam as concepções construídas acerca do corpo feminino negro, isto é, de que maneira o fato de as mulheres negras estarem mais sujeitas às desigualdades interseccionais de raça/cor, gênero e classe despertavam nas/os entrevistadas/ os a atenção para o cuidado a ser dispensado a este grupo de mulheres.

As ideias associadas ao núcleo de sentido diversidade foram corpo e classe. Aqui destacaremos classe, que se referiu, por um lado, às características socioeconômicas das usuárias como garantidoras da diversidade e, por outro lado, como características que se sobrepõem ao caráter racial no que tange à assistência prestada às mulheres que acessam à maternidade. 
Apresentam diferenças sim! Diferenças na questão socioeconômica, você vê que algumas são bem humildes, outras nem tanto, pelo menos, assim, na aparência, no jeito de falar, um pouco mais instruídas, outras completamente sem instrução alguma. [...] Acho que tem muita diversidade nessa questão socioeconômica. Raça também, a gente atende a qualquer tipo de clientela [...]. Até no Brasil, né? A gente tem todo o tipo de raça... (Profissional 1).

Tem bastante diversidade sim. A gente já fez parto aqui de fisioterapeuta, de professora. Realmente é um público que, com a perda de convênios e a crise que houve, eles estão procurando o serviço público, né? Não é só paciente carente que temos aqui não. (Profissional 7).

Aqui a gente tem essa diversidade. Você vê vários níveis. De pacientes até drogadas, muito consumidoras de [...], até pacientes de classe média que você vê que tem até [...]. Hoje em dia você vê muitas universitárias. (Profissional 8).

Nessa maternidade eu vejo que tem uma diferença muito grande de maternidades onde não é o acesso ao SUS, né? Aqui a gente vê muita paciente com menos de 18 anos em trabalho de parto ou em processo de abortamento, então eu acho que a idade das pacientes desta maternidade é, em média, inferior a maternidades particulares ou maternidades que não tenham acesso vinculado ao SUS. (Gestor/a 2).

A ideia associada à classe prevaleceu como aquela responsável pelas desigualdades sociais impostas às mulheres de maneira geral. As respostas se centraram na constatação da diversidade pelo fator socioeconômico. Esta tendência desconsidera as desigualdades estruturais nas quais as mulheres negras são personagens centrais.

Pensar as desigualdades no âmbito estrutural, isto é, socio-histórico, significa pensá-las a partir das formas de conceber, gestar, parir e nascer das pessoas negras. Esses fatores não podem ficar fora das análises sobre o corpo feminino negro e sua dinâmica na assistência à saúde com destaque para o período gravídico puerperal.

O ideário culturalista freyriano contou com o contraponto das teorias que alinharam fatores econômicos, sociais, culturais e políticos às assimetrias raciais, nas quais a democracia racial passou a ser classificada como mito que contribuía para a preservação das distâncias sociais entre brancos e negros. Estes estudos (HASENBALG, 1988; VALLE SILVA, 1988) partiam do princípio de que, ao invés de uma harmonia racial, o que se verificava no Brasil era um grande abismo social baseado não só na cor dos sujeitos, mas, também, na engenharia socioeconômica, absolutamente desigual para a população negra.

Neste caminho, destaca-se a contribuição de Lélia Gonzalez, que apontou outra concepção sobre a imagem social das mulheres negras no 
Brasil. A neurose cultural brasileira é destrinchada por Gonzalez (1984) através do aprofundamento das formas de cristalização da imagem estereotipada da mulher negra brasileira. Estereótipos condicionados e determinados pela relação racista, patriarcal e patrimonial. A autora questiona a democracia racial e os motivos da forte adesão a este conceito, já que, nitidamente, a articulação entre racismo e sexismo produz efeitos violentos para as mulheres negras.

A intersecção entre gênero, raça/cor e classe é tratada por Gonzalez (1984) através do tripé "mulata, doméstica, mãe-preta", em que ela procura demonstrar que a perspectiva socioeconômica elucida questões raciais e vice-versa. Nas análises de Gonzalez (1984), a naturalização do racismo coloca o corpo feminino negro em lugares como os de cozinheira, faxineira, servente ou prostituta. Tais figuras indicariam como estes corpos estariam dispostos no mercado de trabalho e no mercado da conjugalidade. Esta última questão liga-se diretamente ao fator sexual e reprodutivo das mulheres negras, recorrentemente identificadas como mulatas.

A reflexão realizada por Gonzalez (1984) há 35 anos se mostra atual ao se pensar a intersecção "mulata, doméstica e mãe-preta". Tal articulação faz sentido por relacionar-se com as condições de trabalho, reprodução e cuidado às quais estas mulheres estão sujeitas no Brasil, pois é através da perspectiva sócio-histórica, com base na violência da colonização e da escravidão, que será possível verificar seus reflexos concretos na vida destas mulheres. Estes reflexos se apresentam nas unidades de saúde, especialmente nas maternidades, onde as desigualdades de gênero, raça/cor e classe vão se apresentar.

As mulheres negras são, em sua maioria, chefes de suas famílias. São a base da pirâmide social e econômica do país. De acordo com o censo de 2010, realizado pelo IBGE (2010), as mulheres negras representam 55,6 milhões de brasileiras, sendo que a participação das mesmas no mercado de trabalho expõe a desigualdade de gênero e raça que influenciam a capacidade de provimento dos domicílios chefiados por este grupo. $\mathrm{O}$ Dossiê mulheres negras: retrato das condições de vida das mulheres negras no Brasil (IPEA, 2013) revela que:

No entrecruzamento de raça e gênero, observa-se que há um forte contingente de mulheres pretas e pardas no serviço doméstico, enquanto os homens negros estão fortemente concentrados na indústria tradicional (especialmente indústria da construção) e nos serviços gerais em que há baixos salários e um alto grau de informalidade (IPEA, 2013, p. 67).

Teixeira (2018) revela que o atual contexto de crise econômica atinge de forma mais intensa as mulheres negras e jovens, pois $50 \%$ do total de 14,1 milhões de desempregados em 2017 são mulheres, sendo $63,2 \%$ delas negras. No primeiro trimestre de 2018 o desemprego atingiu 
$73 \%$ das mulheres. Entre as negras, o percentual foi de $96 \%$. O emprego formal caiu de $39,8 \%$ para $36,8 \%$ entre as mulheres brancas, e de $32,2 \%$ para $30,5 \%$ entre as negras.

No que diz respeito à imagem da doméstica, é interessante notar como esta categoria laboral, historicamente representada pelas mulheres negras, se apresenta contemporaneamente: queda do número de trabaIhadoras domésticas com carteira assinada, ao mesmo tempo em que houve aumento de $11,7 \%$ no número de domésticas sem registro em carteira. Já o trabalho por conta própria cresceu $17,6 \%$ entre as mulheres negras e $10 \%$ entre as brancas (TEIXEIRA, 2018).

Lima (2012) argumenta que, embora haja uma reconhecida rigidez de classe no Brasil, estudos apontam que essa ganha aspectos de rigidez racial nas tentativas de aquisição ou manutenção de status elevado nas chances de mobilidade, na maior desigualdade racial entre mais escolarizados, em posições ocupacionais de maior status e na maior probabilidade de perder posição social. Assim, as desigualdades raciais se manifestam na procura por emprego e também na condição de empregador/a e de proprietários/as, bem como em posições de comando e chefia. Todos estes aspectos têm sido denunciados pelo movimento de mulheres negras ao longo de sua existência.

Na contramão do que é reivindicado pelas mulheres negras, os depoimentos das/os entrevistadas/os ficaram aquém da possibilidade de intersecção dos determinantes socioeconômicos, raciais e políticos que incidem sobre as usuárias "humildes", "sem instrução alguma", "menores em abortamento", "carentes", "drogadas". Houve o conforto maior em identificar a diversidade "nivelando-a por cima" ao se verbalizar que fisioterapeutas, professoras e as mais instruídas, destacadas pela aparência e pelo modo de falar, foram ali atendidas, sem ter números que constatem quantas mulheres com este perfil foram assistidas.

Reconhece-se que houve maior procura pelos serviços públicos de saúde diante da radical crise econômica verificada no Brasil a partir de 2014. Muitas famílias perderam poder de consumo; um dos reflexos foi a queda da aquisição da saúde enquanto mercadoria. Além disso, infere-se que há maior possibilidade de realizar o parto normal das unidades do SUS por conta das políticas de valorização do parto humanizado. Tal fato faz com que mulheres que desejem ter este tipo de parto recorram às maternidades com referências e casas de parto.

Diante destes resultados é possível verificar que os desafios que envolvem a incorporação das contribuições do movimento de mulheres negras se apresentam de forma intensa. $\mathrm{O}$ alcance da equidade, a partir da assistência isenta de vieses raciais, de gênero e classe, pressupõe aprofundamentos nos significados da diversidade. As iniciativas de combate ao racismo e, em consequência, à violência obstétrica estão presentes em políticas legitimadas pelo Estado, tais como a PNSIPN, que preconiza a garantia do 


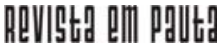

\} ENFRENTAMENTO À VIOLÊNCIA - SANTOS, J. F. A. \}

DOI: $10.12957 /$ rep.2021.56082

cuidado à saúde centrada nas mulheres, familiares e comunidade, ampliando as possibilidades da melhor assistência obstétrica. No entanto, o ideário de democracia racial tende a escamotear desigualdades estruturais da sociedade brasileira. A partir do exposto, a importância da luta política, econômica, social e cultural encabeçada pelas mulheres negras deve ser incorporada de maneira urgente e efetiva pela gestão e execução da política de saúde, sobretudo na saúde sexual e reprodutiva baseada na justiça social.

\section{Considerações finais}

O presente artigo teve como objetivo ressaltar a necessidade de apropriação das contribuições do movimento de mulheres negras por parte de gestoras/es e profissionais de saúde para a efetivação da equidade racial no que se refere à assistência ao parto. Neste contexto, faz sentido referenciar Carneiro (2006, p. 22) quando diz que:

[...] falar de saúde é dar expressão ao corpo. É escutá-lo como corpo expressivo, sensível, vulnerável, transcendente. Falar de saúde da mulher negra é também falar do corpo estético, pois, é do corpo marcado por experiências pessoais singulares de exclusão, pelos poderes sociais hostis - de onde parte o poder e a ética da mulher negra... Designar a diferença racial como direito afirmado nas lutas das muIheres por acesso a atendimento digno à saúde, integridade corporal, autonomia e respeito aos valores e crenças é apontar formas diversas e criativas de inclusão.

Nossos passos vêm de longe, título do texto cujo fragmento foi citado acima, é considerado o sentido ancestral de resistência que impulsiona mulheres negras, nas mais variadas vertentes deste movimento social. Além de contribuir a partir de ações e proposições, mulheres negras têm contribuído, também, com a produção de conhecimento através de estudos que oferecem subsídios para a qualificação da política de saúde numa perspectiva antirracista e antissexista.

A despeito das ricas fontes de informações possibilitadas pelo movimento de mulheres negras, os resultados da pesquisa Enfrentamento à violência obstétrica contra mulheres negras numa maternidade pública municipal do Rio de Janeiro na perspectiva de gestoras/es e profissionais de saúde demostraram a ínfima apropriação das necessidades das mulheres negras na assistência obstétrica.

As percepções das/os profissionais de saúde e gestoras/es quanto à diversidade e às particularidades das mulheres público-alvo da maternidade demonstram que as condições socioeconômicas são as mais apontadas no que se refere ao entendimento sobre as diferenças, demonstrando a ideia clássica de que as pessoas são discriminadas porque são pobres. Nesta 
dimensão, características como: a aparência, o nível educacional, a formação profissional, as expressões verbais e corporais, a diferença entre usuárias do SUS e usuárias do sistema privado, o uso ou não de drogas e a idade delimitam o perfil das usuárias do serviço.

É interessante notar que os sentidos atribuídos à diversidade e à particularidade das mulheres giram em torno, a priori, apenas da dimensão socioeconômica, afirmando que o caráter racial não se relaciona a tais aspectos. A retração da economia é retratada nas falas ao identificarem que, com a impossibilidade de se manterem os planos de saúde, mulheres que até então não utilizavam maternidades públicas passaram a fazê-lo, o que tem trazido outro perfil de usuárias ao serviço.

Porém, ao se considerar o conceito de interseccionalidade, é possível compreender a existência do viés racial. Assim, cabem algumas reflexões: quando é referida a aparência das usuárias, qual o critério definiria a aparência favorável? Ao se afirmar que algumas mulheres têm instrução e outras nem tanto, quais mulheres seriam as menos instruídas? Ao se referirem à pouca idade das pacientes que chegam em processo de abortamento ou em trabalho de parto, qual seria a cor/raça destas usuárias? Qual seria a cor/raça e o número das mulheres de classe média, universitárias, fisioterapeutas e professoras atendidas na maternidade? Quais seriam as relações entre o corpo feminino negro colonial de outrora e o corpo feminino negro que gesta e pare nos dias atuais?

Neste sentido, faz-se urgente incorporar e efetivar ações como a PNSIPN, política esta que contou com o empenho de mulheres negras e de sua luta política. A PNSIPN oferece subsídios para tal incorporação, porém, os efeitos do racismo estrutural têm dificultado a efetivação de tal política por todas as instâncias do SUS.

Estes obstáculos requerem estratégias que garantam integração das pessoas negras nos serviços de saúde. No que diz respeito à assistência ao período gravídico puerperal sugerem-se ações educativas articuladas entre a educação permanente em saúde e a saúde das mulheres negras. Tal ação materializa a integralidade e a intersetorialidade, princípios fundamentais do SUS. Neste sentido, é preciso investimento na gestão e na execução da assistência obstétrica que favoreça a prática profissional baseada em evidências, de modo que, cotidianamente, profissionais de saúde e gestoras/ es repensem suas ações para melhorar o cuidado de saúde, tornando eficaz a experiência das mulheres negras, numa perspectiva de justiça reprodutiva. É recomendável, ainda, que todos os sujeitos envolvidos na política de saúde tenham em vista os fundamentos do controle social, ou seja, da participação da sociedade para intervir no SUS. A participação do movimento de mulheres negras não pode deixar de ser considerada nesta dinâmica. 


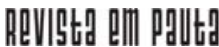

\} ENFRENTAMENTO À VIOLÊNCIA - SANTOS, J. F. A. \}

DOI: $10.12957 /$ rep. 2021.56082

\section{Referências}

ALMEIDA, M. da S. Desumanização da população negra: genocídio como princípio tácito do capitalismo. Em Pauta, Rio de Janeiro, v. 12, n. 34, 2014. Disponível em: http://oaji.net/articles/2015/281-1432671327.pdf. Acesso em: 2 mar. 2017.

ARAÚJO, M. J. de O. Reflexões sobre a saúde da mulher negra e o movimento feminista, 2001. Disponível em: http://www.antroposmoderno.com/antroversion-imprimir.php?id_articulo=315. Acesso em: 30 set. 2017.

BRASIL. Ministério da Saúde. Política nacional de saúde integral da população negra: uma política para o SUS. Brasília: Editora do Ministério da Saúde, 2013. Disponível em: http://bvsms.saude.gov.br/bvs/publicacoes/ politica_nacional_saude_integral_populacao.pdf>Acesso em: 17 ago. 2017.

CARNEIRO, F. Nossos passos vêm de longe... In: WERNECK, J.; MENDONÇA, M.; WHITE, E. C. O livro da saúde das mulheres negras: nossos passos vêm de longe. Rio de Janeiro: Pallas, 2006.

COLETIVO MARGARIDA ALVES. Guia de Defesa Popular da Justiça Reprodutiva, 2020. Disponível em: https://www.mulheres.org.br/wp-content/ uploads/2020/02/guia-defesa-popular-justica-reprodutiva.pdf. Acesso em: 18 nov. 2020.

ENFRENTAR. In: MICHAELIS Dicionário Online. 2020. Disponível em: http:/ /michaelis.uol.com.br/busca? $\mathrm{r}=0 \& \mathrm{f}=0 \& \mathrm{t}=0 \&$ palavra $=$ enfrentar. Acesso em: 10 set. 2020.

GELEDES. Carta das mulheres negras 2015. São Paulo: Geledes, 2015. Disponível em: https://www.geledes.org.br/carta-das-mulheres-negras-2015/. Acesso em: 10 set. 2020.

GOMES, R. Análise e interpretação de dados de pesquisa qualitativa. In: MINAYO, C. de S. et al. Pesquisa social: teoria, método e criatividade. Petrópolis: Vozes, 2016.

GONZALEZ, L. Racismo e sexismo na cultura brasileira. In: SILVA, L. A. M. (Org.). Movimentos sociais e urbanos, minorias étnicas e outros estudos. Brasília: ANPOCS, 1984.

HASENBALG, C. e SILVA, N. do V. Estrutura Social, Mobilidade e Raça. Rio de Janeiro: luperj/Vértice, 1988.

IBGE. Censo 2010: resultados. 2010. Disponível em: https://censo2010 .ibge.gov.br/resultados.html. Acesso em: 18 nov. 2017.

IPEA. Dossiê mulheres negras: retrato das condições de vida das mulheres negras no Brasil. Brasília: Ipea, 2013. Disponível em: http:// 
www.ipea.gov.br/igualdaderacial/index.php?option=com_ content $\& v i e w=$ article\&id=731. Acesso em: 10 abr. 2016.

LEAL, M. do C. et al. A cor da dor: iniquidades raciais na atenção pré-natal e ao parto no Brasil. Cadernos de Saúde Pública, Rio de Janeiro, v. 33, supl. 1, 2017. Disponível em: http://www.scielo.br/scielo.php?script= sci_arttext\&pid=S0102-311X2017001305004\&lng=en\&nrm=iso. Acesso em: 9 mar. 2020.

LIMA, M. "Raça" e pobreza em contextos metropolitanos. Tempo Social, São Paulo, v. 24, n. 2, nov. 2012. Disponível em: http://www.scielo.br/ scielo.php?script=sci_arttext\&pid=S0103-20702012000200012\&Ing =en\&nrm=iso. Acesso em: 10 set. 2020.

LOPES, F.; WERNECK, J. Saúde da população negra: Da conceituação às políticas públicas de direito. In: WERNECK, J. (Org.). Mulheres Negras: um olhar sobre as políticas sociais no Brasil. Rio de Janeiro: CRIOLA, 2009. Disponível em https://criola.org.br/wp-content/uploads/2017/10/livro_ mulheresnegras_1_.pdf. Acesso em: 23 nov. 2020.

NASCIMENTO, E. L. O sortilégio da cor: identidade, raça e gênero no Brasil. São Paulo: Selo Negro, 2003.

REDE PARTO DO PRINCÍPIO. Violência obstétrica: parirás com dor. Brasília, 2012. Disponível em: http://www.senado.gov.br/comissoes/docu mentos/SSCEPI/DOC\%20VCM\%20367.pdf. Acesso em: 20 ago. 2015.

TEIXEIRA, M. Mulheres negras sofrem mais com trabalho precário e falta de investimentos. CUT Notícias, São Paulo, 2018. Disponível em: https:// www.cut.org.br/noticias/tres-anos-de-perdas-e-retrocessos-paras-asmulheres-d94a. Acesso em: 20 ago. 2019.

WERNECK, J. Nossos passos vêm de longe! Movimentos de mulheres negras e estratégias políticas contra o sexismo e o racismo. In: VERSCHUUR, C. (Org.). Vents d'Est, vents d'Ouest: mouvements de femmes et féminismes anti-coloniaux. Genève: Graduate Institute Publications, 2009. Disponível em: https://books.openedition.org/iheid/6316. Acesso em: 9 mar. 2020.

DOI: $10.12957 /$ rep.2021.56082

Recebido em 09 de março de 2020.

Aprovado para publicação em 22 de maio de 2020.

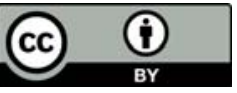

A Revista Em Pauta: Teoria Social e Realidade Contemporânea está licenciada com uma Licença Creative Commons Atribuição 4.0 Internacional. 